\title{
1986 SPRING WHOOPING CRANE MIGRATION - PRAIRIE PROVINCES
}

BRIAN W. JOHNS. Canadian Wildlife Service, 115 Perimeter Road, Saskatoon, Saskatchewan. S7N 0X4

The endangered Whooping Crane has been the subject of much study during its struggle back from the brink of extinction. Much of this research has been concentrated on the breeding grounds in Wood Buffalo National Park and the wintering area on Aransas National Wildlife Refuge, Texas.
In an effort to increase our knowledge of Whooping Crane staging areas in prairie Canada, the Canadian Wildlife Service established a Whooping Crane Hot Line in Saskatoon (306-975-5595) to receive reports of migrating cranes from across the prairies (Blue Jay 44:47). An observer is asked to leave a name and

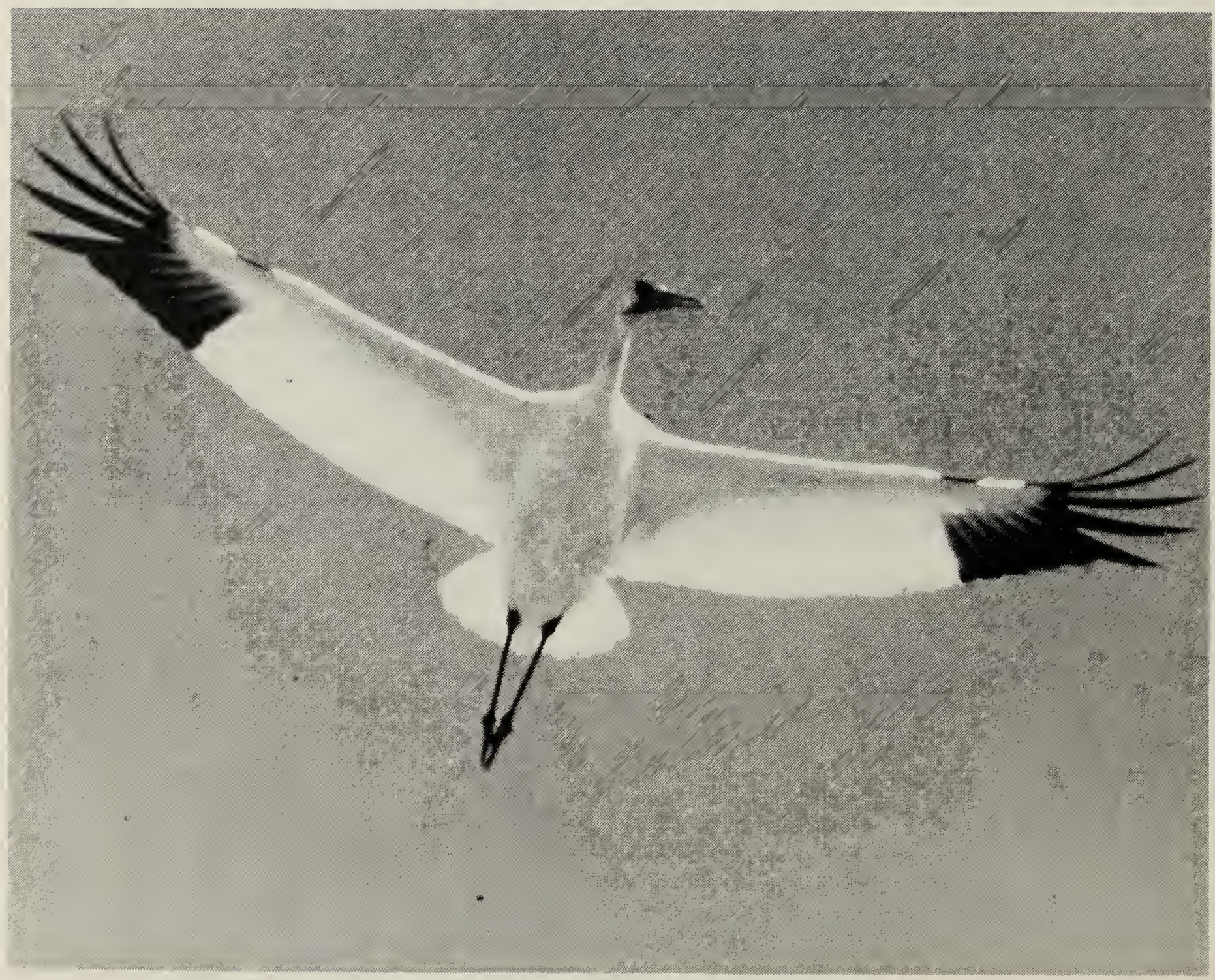




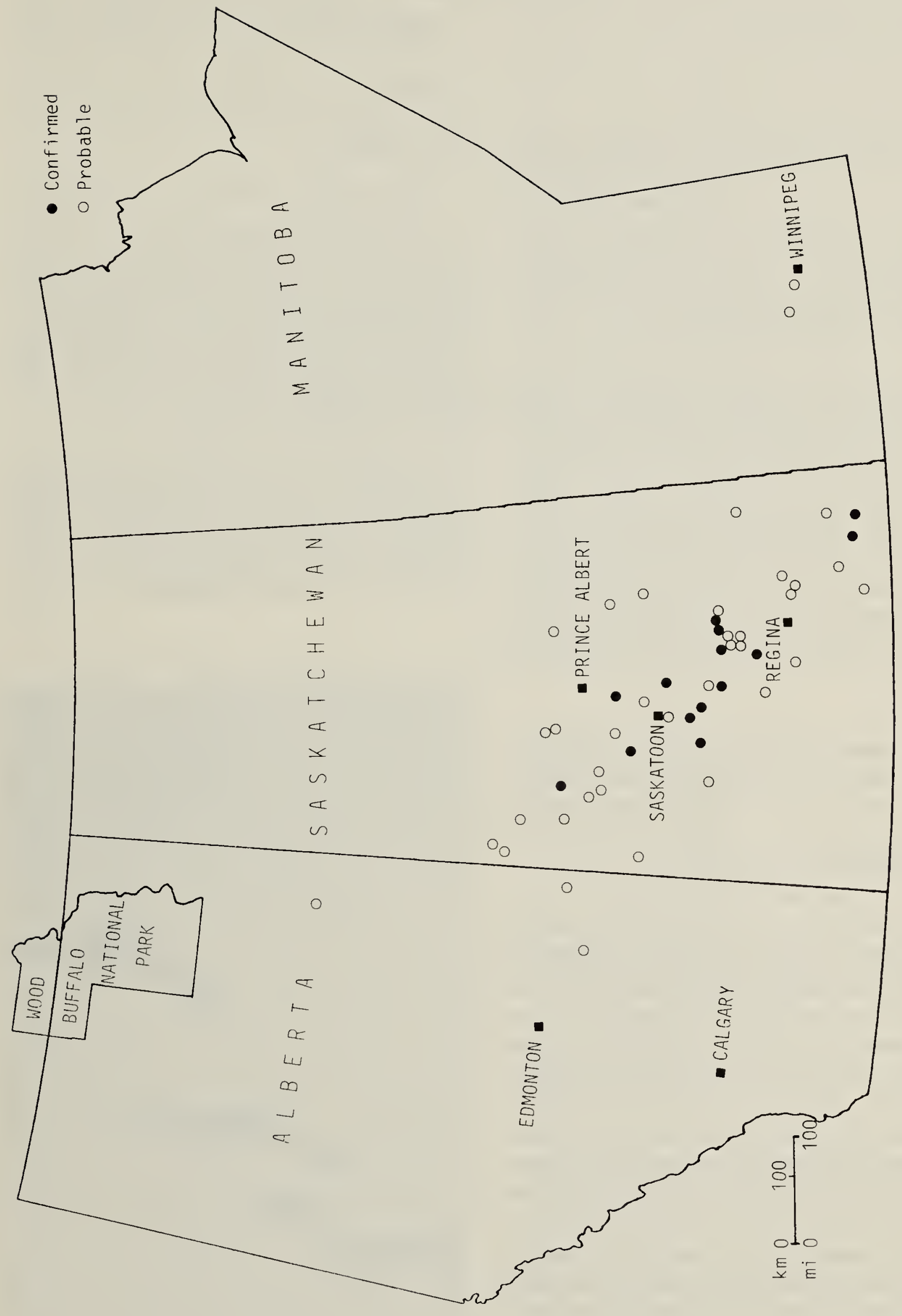

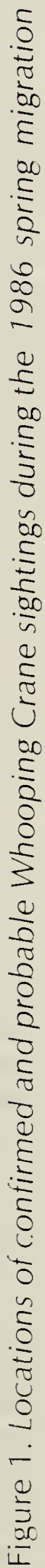


telephone number; a return call will be made to obtain details. With the aid of the hot line and its associated publicity, reports of birds believed to be Whooping Cranes began the first week of April and continued until late May, 1986. Sightings increased over previous years from an average of less than 20 per spring migration to more than 100 . The most important outcome of the new reporting system is the increase in confirmed sightings. Fourteen reports were confirmed, 36 were probables and 33 were unconfirmed. The remainder were of several species which have a similar appearance.

Three of the reports were of colourbanded birds. A subadult banded in 1984 was observed near Govan on 12 April by Bob Turner and Fred Lahrman. The other two birds were banded in 1985. One of these was seen near Ardath from 11-17 April with two unbanded adults, while the second was observed near Colonsay from 13-17 April with 4 unbanded adults. Locations of other confirmed and probable sightings are plotted in Figure 1.

We were also able to gather important information on feeding and roosting locations used by the cranes. Reports of flying birds help to identify the corridor and the timing of migration.

Information is also required on fall migration. This migration through the prairies usually occurs between midSeptember and late October. Whoopers however, may begin migrating in late August, and linger until early November.

Swans, pelicans and snow geese are frequently mistaken for Whooping Cranes. An adult Whooping Crane is snowy white and stands almost $1.5 \mathrm{~m}(4.5 \mathrm{ft})$ tall. Young birds, usually associated with the adults, have varying amounts of brown on them. The most distinctive characteristic of flying cranes is the white plumage with contrasting black wingtips (all 10 primary feathers). Their long necks are extended forward and long legs trail behind. Their flight is either flapping with shallow wing beats or spiralling upwards and gliding. The wingspan of a Whooping Crane measures $2.3 \mathrm{~m}$ (7.5 ft.), similar to a swan or a pelican. Whoopers usually migrate as singles, pairs or family groups of three, but occasionally concentrate in flocks of up to 11 birds.

Could anyone seeing a Whooping Crane please report the sighting as soon as possible. Observations can be reported anytime to the 24hour answering service. Sightings reported to local offices of provincial wildlife agencies, museums and the RCMP are all forwarded to the Canadian Wildlife Service.

I wish to acknowledge the excellent cooperation of many individuals who reported migrating Whooping Cranes. Success of this project depends on the help of numerous volunteers.

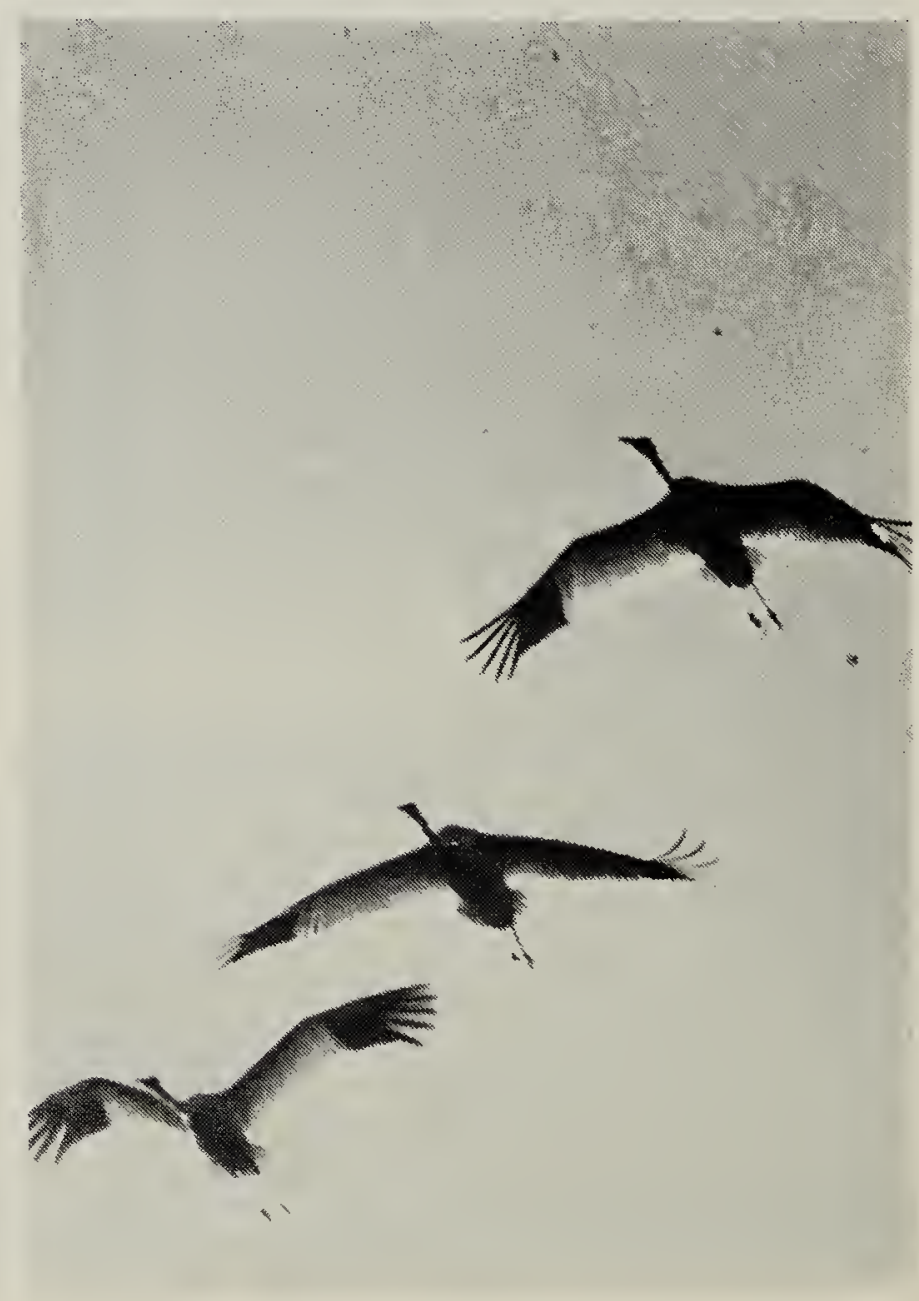

Whooping Cranes

Fred W. Lahrman 